\title{
Metabolome analysis reveals a role for glyceraldehyde 3-phosphate dehydrogenase in the inhibition of $C$. thermocellum by ethanol
}

\author{
Liang Tian ${ }^{1,3}$, Skyler J. Perot ${ }^{2,3}$, David Stevenson 4,3, Tyler Jacobson ${ }^{4,3}$, Anthony A. Lanahan 1,3, \\ Daniel Amador-Noguez ${ }^{4,3}$, Daniel G. Olson ${ }^{1,3^{*}}$ and Lee R. Lynd ${ }^{1,3^{*}}$
}

\begin{abstract}
Background: Clostridium thermocellum is a promising microorganism for conversion of cellulosic biomass to biofuel, without added enzymes; however, the low ethanol titer produced by strains developed thus far is an obstacle to industrial application.

Results: Here, we analyzed changes in the relative concentration of intracellular metabolites in response to gradual addition of ethanol to growing cultures. For C. thermocellum, we observed that ethanol tolerance, in experiments with gradual ethanol addition, was twofold higher than previously observed in response to a stepwise increase in the ethanol concentration, and appears to be due to a mechanism other than mutation. As ethanol concentrations increased, we found accumulation of metabolites upstream of the glyceraldehyde 3-phosphate dehydrogenase (GAPDH) reaction and depletion of metabolites downstream of that reaction. This pattern was not observed in the more ethanoltolerant organism Thermoanaerobacterium saccharolyticum. We hypothesize that the Gapdh enzyme may have different properties in the two organisms. Our hypothesis is supported by enzyme assays showing greater sensitivity of the C. thermocellum enzyme to high levels of $\mathrm{NADH}$, and by the increase in ethanol tolerance and production when the $T$. saccharolyticum gapdh was expressed in C. thermocellum.
\end{abstract}

Conclusions: We have demonstrated that a metabolic bottleneck occurs at the GAPDH reaction when the growth of C. thermocellum is inhibited by high levels of ethanol. We then showed that this bottleneck could be relieved by expression of the gapdh gene from T. saccharolyticum. This enzyme is a promising target for future metabolic engineering work.

Keywords: Consolidated bioprocessing, Clostridium thermocellum, Ethanol tolerance, Metabolomic analysis

\section{Background}

Plant biomass is of interest as a feedstock for sustainable production of liquid fuels and organic chemicals [1]. Consolidated bioprocessing (CBP), in which biomass solubilization and fermentation are accomplished in one step, without added enzymes, is a promising processing configuration for low-cost biological conversion of plant biomass [2-5]. As a candidate organism for CBP, Clostridium thermocellum is among the most effective

\footnotetext{
*Correspondence: dan268@gmail.com; lee.r.lynd@dartmouth.edu

1 Thayer School of Engineering, Dartmouth College, 14 Engineering Drive, Hanover, NH 03755, USA
}

Full list of author information is available at the end of the article microorganisms, described to date, for lignocellulose deconstruction [6,7]. Different approaches have been applied to engineer $C$. thermocellum to produce ethanol at high yield and titer, including eliminating native by-products, overexpressing native genes, introducing heterologous genes, and adaptive evolution [8-13]. However, the highest reported ethanol titer produced by this microbe in pure culture is $27 \mathrm{~g} / \mathrm{L}$, which is below the titer of $40 \mathrm{~g} / \mathrm{L}$ widely assumed to be necessary for commercial application [14]. Substantially higher titers, e.g., $70 \mathrm{~g} / \mathrm{L}$, have been produced by engineered strains of Thermoanaerobacterium saccharolyticum, a hemicellulose-fermenting thermophilic anaerobe [15]. 
Ethanol inhibition has been extensively studied in bacteria, and several mechanisms have been proposed, including membrane fluidization, disruption of proton motive force and ATP generation, disruption of nicotinamide cofactor ratios, and inhibition of key metabolic enzymes [16, 17]. Wild-type $C$. thermocellum is unable to initiate growth when inoculated into medium containing ethanol at concentrations of $20 \mathrm{~g} / \mathrm{L}$ or higher $[10,18,19]$. Strains adapted for improved tolerance by serial transfer over a period of several weeks have been shown to initiate growth in the presence of 50-55 g/L ethanol [18-22]. In C. thermocellum, the mechanism of tolerance has been attributed to both changes in membrane properties [19, 20, 23, 24], and metabolic enzymes, in particular, the bifunctional acetaldehyde-CoA/alcohol dehydrogenase gene $(a d h E)[18,21]$. In a similar organism, Thermoanaerobacter thermohydrosulfuricus, Lovitt et al. found that selection for ethanol tolerance resulted in several metabolic changes, including the elimination of NADH-linked alcohol dehydrogenase (ADH-NADH) activity, elimination of Ferredoxin-NAD ${ }^{+}$activity, and a change in the properties of the Gapdh enzyme that made it less sensitive to inhibition by NADH [25]. The genetic basis of the elimination of ADH-NADH activity was not determined; however, it is reasonable to suspect that this may have been due to a mutation in the $a d h E$ gene.

Although ethanol tolerance has often been studied as a proxy for ethanol production, many studies have found that increases in ethanol tolerance have no effect on ethanol production [26-28], including studies of $C$. thermocellum [29]. Furthermore, in cases where ethanol tolerance has been improved by selection, many of the improvements appear to be due to idiosyncratic mutations whose effects are not generalizable to other strain backgrounds or growth conditions $[17,26]$.

Thus, we have focused our inquiry on facets of ethanol tolerance that are relevant to high titer production, such as metabolism. Recent advances in analytical chemistry have allowed for measurement of many of the intracellular metabolites involved in glycolysis and fermentation (i.e., metabolomics) [30]. Metabolomic analysis has been used to investigate the short-term effect of ethanol inhibition on C. thermocellum by Yang et al. [31]. They found that a pulse of added ethanol ("ethanol shock") of about $4 \mathrm{~g} / \mathrm{L}$ was sufficient to temporarily halt growth, and found intracellular accumulation of fructose-6-phosphate and glucose-6-phosphate. Since they only measured two intracellular metabolites related to glycolysis and fermentation, however, they were unable to precisely determine the location of the metabolic disruption. Furthermore, since C. thermocellum is known to be able to tolerate much more than $4 \mathrm{~g} / \mathrm{L}$ ethanol, it suggests that at least some of the effects observed by Yang et al. were due to the sudden addition of ethanol rather than its absolute titer.

Factors associated with the cessation of fermentation in C. thermocellum include accumulation of ethanol [10] and other fermentation products [32] as well as nutrient limitation [33]. Accumulation of salt added to neutralize acid production was found to limit fermentation by Thermoanaerobacterium thermosaccharolyticum at highfeed xylose concentrations in continuous culture [34]. Fermentation in C. thermocellum is repeatedly observed to stop at ethanol concentrations well below those that can be tolerated by adapted strains. This phenomenon, referred to as a "titer gap" [3], remains to be explained. In this work, we applied the tools of metabolomics and genetic engineering to pursue the question: "what limits ethanol production at high titer?"

\section{Methods}

\section{Bacterial strains, media, and growth conditions}

Strains used in this study are listed in Additional file 1: Table S1. Plasmids and primers are listed in Additional file 2: Table S2 and Additional file 3: Table S3. All chemicals were reagent grade or better and obtained from Sigma-Aldrich (St. Louis, MO, USA) or Fisher Scientific (Pittsburgh, PA, USA) unless indicated otherwise. CTFUD-rich medium at $\mathrm{pH} 7.0$ and $\mathrm{pH} 6.0$ was used for C. thermocellum and T. saccharolyticum strain maintenance, respectively [35]. For metabolomic analysis, $C$. thermocellum was grown LC medium [36] and T. saccharolyticum was grown in modified MTC-6 medium [9, 37]. The growth temperature was $55^{\circ} \mathrm{C}$ for both strains. Bioreactor fermentations to measure ethanol inhibition were carried out in 250-mL bioreactors (NDS, Vineland, NJ, USA).

Avicel fermentations to measure ethanol production were carried out in 1.5-L (1-L working volume) Sartorius Biostat A-plus Sartorius Stedim (Sartorius Stedim, Bohemia, NY, USA) bioreactors in modified MTC-5 medium without MOPS buffer and with $2 \mathrm{~g} / \mathrm{L}$ urea as the nitrogen source, with the temperature maintained at $55^{\circ} \mathrm{C}$ and stirred at $150 \mathrm{rpm}$. The $\mathrm{pH}$ was controlled at 6.5 with a Mettler-Toledo $\mathrm{pH}$ probe (Columbus, $\mathrm{OH}, \mathrm{USA}$ ) by the addition of $8 \mathrm{~N} \mathrm{KOH} \mathrm{[10].}$

\section{Ethanol tolerance assay}

Each strain was cultured in a single bioreactor until the $\mathrm{OD}_{600}$ reached 0.1-0.2. Then the culture was split and transferred into two bioreactors (we refer to this as time T0). At this time, a feed of pure, deoxygenated ethanol was pumped into one of the bioreactor at the rate of $5 \mathrm{~g} / \mathrm{L} / \mathrm{h}$, meanwhile, deoxygenated water was pumped to the other bioreactor as control. A Cole-Parmer peristaltic pump was used for pumping (Vernon Hills, IL, USA). 
Both the ethanol and water were kept in serum bottles and purged with pure $\mathrm{N}_{2}$ gas before using. Since ethanol and water have different densities, the volumetric flow rate of each pump had to be calibrated independently to assure identical mass flow rates.

Intracellular metabolite samples were collected by the filter technique described by Olson et al. [38]. The extraction solution was a 2:2:1 ratio of acetonitrile:methanol:water. A volume of $2-10 \mathrm{~mL}$ of culture was transferred to a $0.45-\mu \mathrm{m}$ nylon membrane filter (EMD Millipore, Billerica, MA, USA) and vacuumfiltered. After excess medium had been removed, the filter was placed in a plastic petri dish with $1.6 \mathrm{~mL}$ cold extraction solution to quench metabolism and extract the metabolites. The extraction solution was kept cold by being placed in contact with a 4-inch-thick aluminum block prechilled to $-80{ }^{\circ} \mathrm{C}$. Sampling of the reactor, filtration, and quenching were all performed in an anaerobic chamber (COY, Grass Lake, MI, USA) with an atmosphere of $85 \% \mathrm{~N}_{2}, 10 \% \mathrm{CO}_{2}$, and $5 \% \mathrm{H}_{2}$ to avoid oxygen exposure during metabolite sampling.

The petri dishes with extraction solution, filter, and cells were placed at $-80{ }^{\circ} \mathrm{C}$ for $1-24 \mathrm{~h}$ to allow a pause in the protocol. They were then thawed and the cells were washed off of the filter by pipetting, using gentle scraping as needed. The cells and extraction solution were transferred to $1.5-\mathrm{mL}$ microcentrifuge tubes and centrifuged at $15,000 \times g$ for $1 \mathrm{~min}$. The supernatant was collected and analyzed by LC-MS to identify and quantify metabolites.

\section{Metabolomics analysis}

Samples were analyzed using an LC-MS/MS system consisting of a Dionex Ultimate 3000 UHPLC coupled by electrospray ionization (ESI; negative mode) to a hybrid quadrupole-high-resolution mass spectrometer (Q Exactive orbitrap, Thermo Scientific) for detection of targeted compounds based on their accurate masses and retention times (matched to purified standards). Liquid chromatography (LC) separation was achieved using an ACQUITY UPLC ${ }^{\circledR}$ BEH C18 $(2.1 \times 100 \mathrm{~mm}$ column, 1.7- $\mu \mathrm{m}$ particle size) and a flow rate of $0.2 \mathrm{~mL} / \mathrm{min}$. Solvent A was 97:3 water:methanol with $10 \mathrm{mM}$ tributylamine (TBA) and approximately $9.8 \mathrm{mM}$ acetic acid, $\mathrm{pH} \sim 8.2$; solvent B was $100 \%$ methanol. Total run time was $24.5 \mathrm{~min}$ with the following gradient: $0 \mathrm{~min}, 5 \% \mathrm{~B}$; $2.5 \mathrm{~min}$, ramp from $5 \%$ B to $95 \%$ B over $14.5 \mathrm{~min}$; hold at $95 \%$ B for $2.5 \mathrm{~min}$; return to $5 \%$ B over $0.5 \mathrm{~min}$; hold at $5 \%$ B for 5 min. All samples were injected twice (analytical replicates). MS scans consisted of full negative mode MS scanning for $m / z$ between 70 and 1000 from time 0 to $18.5 \mathrm{~min}$. Metabolite peaks were identified using Metabolomics Analysis and Visualization Engine (MAVEN) $[39,40]$. Response factors from the standards were used to calculate absolute values of the nicotinamide cofactors and adenosine phosphate cofactors.

\section{qPCR for cell number measurement}

Metabolite concentrations were normalized to cell number. Cell number was determined by qPCR as follows: after taking an initial sample of culture for metabolite measurements, a second sample of culture was taken for cell number measurements. The cells were transferred to a $0.45-\mu \mathrm{m}$ nylon membrane filter and vacuum-filtered, then transferred to a plastic petri dish with $0.5 \mathrm{~mL}$ TE buffer. The cells were washed off of the filter by pipetting, then transferred to a $1.5-\mathrm{mL}$ microcentrifuge tube and washed twice with TE buffer. The washed cells were suspended in $0.5 \mathrm{~mL}$ TE buffer and quantified by qPCR. Serial dilution of the samples was performed to ensure the qPCR signal was within the range of the standard curve.

A synthesized fragment of double-stranded DNA (gBlock ${ }^{\circledR}$, IDT, Coralville, Iowa, USA) was used as standard to quantify DNA levels. The gBlock used for this assay contained part of the $r e c A$ gene sequences from both $C$. thermocellum and $T$. saccharolyticum. The amplicon for each gene was around 120 and 5 bp was added on both sides of each amplicon to avoid secondary structure. The gBlock was first diluted to a concentration of $10 \mathrm{ng} /$ $\mu \mathrm{L}(12 \mathrm{nM})$ and five tenfold dilutions were prepared to make the standard curve.

SsoFast ${ }^{\mathrm{TM}}$ EvaGreen ${ }^{\circledR}$ Supermix (Bio-Rad, Hercules, CA, USA) was used for the qPCR reaction and the assay was run in triplicate in a $10 \mu \mathrm{L}$ reaction volume. The number of cells was determined by comparison of copy number of the $r e c A$ gene with the standard curve, using the assumption that each cell had one copy of its chromosome.

\section{Analytical methods}

Acetate, formate, ethanol, glucose, and residual cellobiose were determined by high-pressure liquid chromatography (HPLC, Waters, Milford, MA) with refractive index detection using an Aminex HPX-87H column (Bio-Rad, Hercules, CA) with a $2.5 \mathrm{mM}$ sulfuric acid solution mobile phase. Pellet nitrogen was determined using a Shimadzu TOCV-CPH total organic carbon analyzer with added total nitrogen unit (Shimadzu Scientific Instruments, Columbia, MD, USA), calibrated using an acidified glycine standard [41].

\section{Heterologous expression of protein in E. coli}

The gapdh genes from C. thermocellum and T. saccharolyticum were amplified by PCR with Q5 DNA polymerase (New England Biolabs, Ipswich, MA, USA). The primers used for each gene are listed in Additional file 3: Table 
S3. Target genes were inserted into plasmid pD861-NH (DNA2.0 Inc., Menlo Park, CA, USA) and tagged with a $5 \times$ His6 cassette. The vector was transformed into $E$. coli BL21(DE3). Cells were grown aerobically in TB medium (Sigma T0918, St. Louis, MO, USA) at $37{ }^{\circ} \mathrm{C}$ with a stirring speed of $225 \mathrm{rpm}$ [9]. When the $\mathrm{OD}_{600}$ reached 0.6, $4 \mathrm{mM}$ rhamnose was added to induce the expression of the target gene. The cells were then grown aerobically for $4 \mathrm{~h}$ before harvesting by centrifugation. The cell pellets were washed with $50 \mathrm{mM}$ Tris- $\mathrm{HCl}$ with $0.5 \mathrm{mM}$ DTT (pH 7.5) and stored at $-80^{\circ} \mathrm{C}$.

The cell pellet was resuspended in lysis buffer $(50 \mathrm{mM}$ sodium phosphate $\mathrm{pH} 7.5,500 \mathrm{mM} \mathrm{NaCl}, 20 \mathrm{mM}$ imidazole, $1 \times$ BugBuster reagent (EMD Millipore, Darmstadt, Germany), and $0.2 \mathrm{mM}$ dithiothreitol [DTT]). The cells were lysed with Ready-Lyse lysozyme (Epicentre, Madison, WI, USA), and DNase I (New England Biolabs, Ipswich, MA, USA) was added to reduce the viscosity. After incubation for $30 \mathrm{~min}$. at room temperature, the resulting solution was centrifuged at $10,000 \times g$ for $5 \mathrm{~min}$. The supernatant was used as cell extract for enzyme purification. Native $E$. coli proteins were denatured by incubation at $55{ }^{\circ} \mathrm{C}$ for $30 \mathrm{~min}$. The denatured proteins were then removed by centrifugation at $10,000 \times g$ for $5 \mathrm{~min}$. His tag affinity spin columns (His SpinTrap; GE Healthcare Bio-Sciences, Pittsburgh, PA, USA) were used to purify the protein. The column was first equilibrated with binding buffer $(50 \mathrm{mM}$ sodium phosphate, $500 \mathrm{mM} \mathrm{NaCl}, 20 \mathrm{mM}$ imidazole, $\mathrm{pH}$ 7.5). Cell extracts were applied to the column, and then the column was washed twice with wash buffer $(50 \mathrm{mM}$ sodium phosphate, $500 \mathrm{mM} \mathrm{NaCl}, 50 \mathrm{mM}$ imidazole, $20 \%$ ethanol, $\mathrm{pH} 7.5$ ). The His-tagged protein was eluted with elution buffer (50 mM sodium phosphate, $500 \mathrm{mM}$ $\mathrm{NaCl}, 500 \mathrm{mM}$ imidazole, $\mathrm{pH}$ 7.5).

\section{GAPDH enzyme assays}

The activity of the glyceraldehyde-3-phosphate dehydrogenase enzyme (GAPDH EC 1.2.1.12) was measured at $55{ }^{\circ} \mathrm{C}$ as previously described [42]. The standard assay (200 $\mu \mathrm{L}$ working volume) contained $50 \mathrm{mM}$ Tris- $\mathrm{HCl}$ $\mathrm{pH}$ 7.0, $10 \mathrm{mM}$ sodium arsenate, $10 \mathrm{mM}$ glyceraldehyde3-phosphate, and $0.5 \mathrm{mM} \mathrm{NAD}{ }^{+}$. To avoid thermal destruction of glyceraldehyde-3-phosphate, this substrate was added to the mixture immediately before starting the enzyme reaction. The formation NADH was followed by photometric observation at $340 \mathrm{~nm}\left(\varepsilon=6.2 \mathrm{mM}^{-1} \mathrm{~cm}^{-1}\right)$ in a BioTek PowerWave XS plate reader (BioTek Instruments Inc., Winooski, VT, USA). The protein concentration was determined using the Bradford protein reagent with bovine serum albumin as the standard (Bio-Rad, Hercules, CA, USA). For the NADH inhibition test, 0 to $0.5 \mathrm{mM}$ of NADH was added to the reaction mix. To avoid the saturating the detector, the wavelength was changed from $340 \mathrm{~nm}$ to $380 \mathrm{~nm}\left(\varepsilon=1.2 \mathrm{mM}^{-1} \mathrm{~cm}^{-1}\right)$.

\section{Results \\ Ethanol tolerance test}

In order to characterize the metabolic response to ethanol, ethanol was added continuously to a growing culture at a rate of $5 \mathrm{~g} / \mathrm{L} / \mathrm{h}$. This rate was chosen to achieve growth inhibition before the substrate carbon was completely consumed. As seen in Fig. 1, the presence of added ethanol reduced the maximum optical density achieved $\left(\mathrm{OD}_{\max }\right)$ and slowed growth. Increasing optical density was observed until the ethanol concentration reached $45 \mathrm{~g} / \mathrm{L}$.

\section{Metabolite analysis}

Samples from the experiment depicted in Fig. 1 were collected at 1-2 $\mathrm{h}$ intervals, and intracellular metabolites were analyzed using LC-MS. The initial timepoint (T0) samples were taken after growth had started and immediately before ethanol addition. As ethanol was added, we observed a marked increase in the ratios of NADH/ $\mathrm{NAD}^{+}$and NADPH/NADP ${ }^{+}$as well as a moderate decline in the energy charge compared to control strains not exposed to ethanol (Fig. 2a, b).

Both the $\mathrm{NADH} / \mathrm{NAD}^{+}$ratio and $\mathrm{NADPH} / \mathrm{NADP}^{+}$ ratios increased significantly as the concentration of added ethanol increased ( $t$ test values of the endpoint samples were $p=0.02$ and $p=0.0003$, respectively) when the ethanol was added to the culture. The observed decrease in energy charge in response to increasing ethanol was highly significant ( $p$ value for the endpoint samples was 0.01) (Fig. 2c).

\section{Comparison of ethanol inhibition in C. thermocellum and $T$. saccharolyticum}

To put the results from $C$. thermocellum in context, we performed the same ethanol inhibition experiment on an engineered strain of $T$. saccharolyticum, an organism that has been shown to be able to produce ethanol at up to $70 \mathrm{~g} / \mathrm{L}$ more than 2.5 times greater than the maximum reported for $C$. thermocellum [15].

For both C. thermocellum and T. saccharolyticum, the relative concentration of 3-phosphoglycerate (3-PG) and phosphoenolpyruvate (PEP) decreased with increasing ethanol, indicative of a flux bottleneck upstream of 3-PG (Fig. 3). Marked differences were observed in the response of other metabolite concentrations. For C. thermocellum, the relative concentrations of the glucose-6-phosphate and fructose-6-phosphate (G6P/F6P) pool, the fructose1,6-phosphate (FBP) pool, and the dihydroxyacetone phosphate (DHAP) pool increased by 7, 16, and 11-fold, respectively, between 0 and $400 \mathrm{~min}(0$ and $40 \mathrm{~g} / \mathrm{L}$ added 


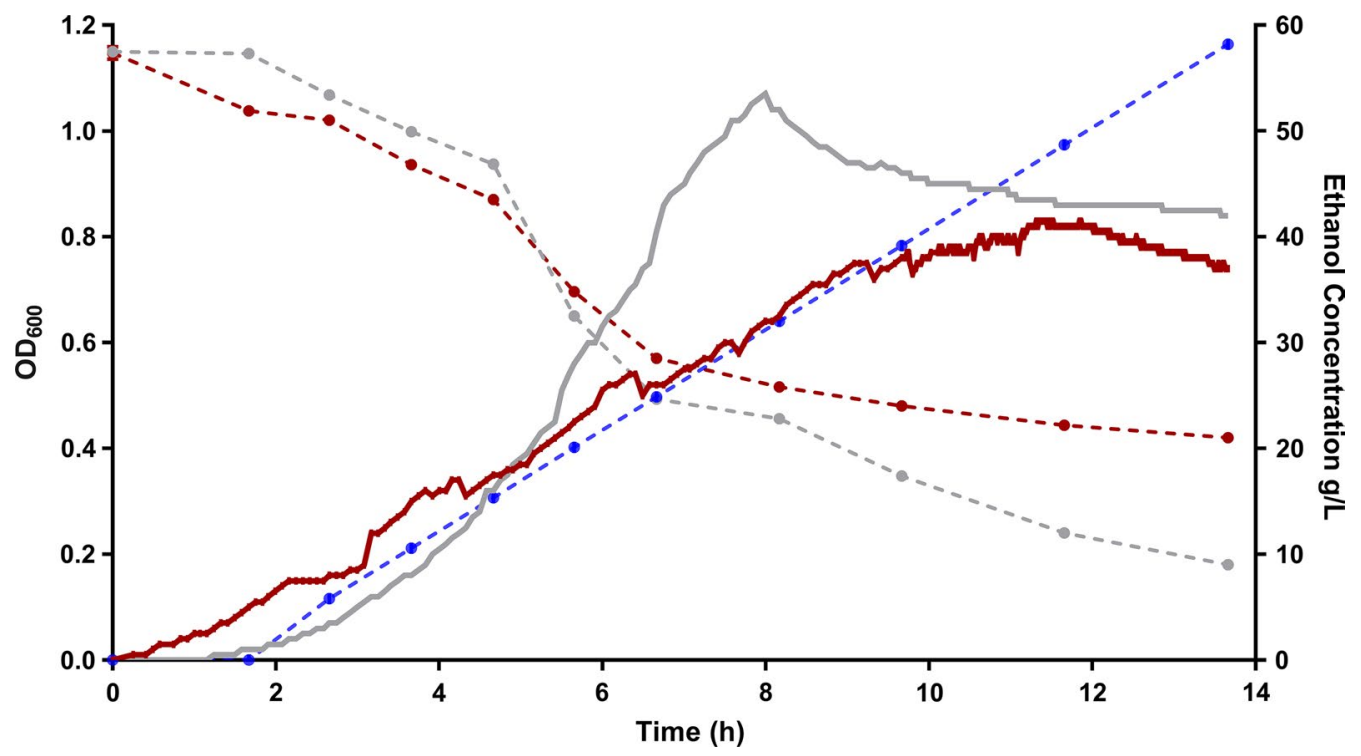

Fig. 1 Growth test in LC medium with $10 \mathrm{~g} / \mathrm{L}$ cellobiose. Ethanol was added to the culture at a rate of $5 \mathrm{~g} / \mathrm{L} / \mathrm{h}$. The blue dashed line indicates the measured ethanol concentration in the culture with ethanol addition. The measured ethanol concentration in the culture without ethanol addition is not shown in the figure, since the final ethanol titer for that culture was only $1.2 \mathrm{~g} / \mathrm{L}$. The data presented here are a representative example of biological triplicates. Similar trends were found in all replicates
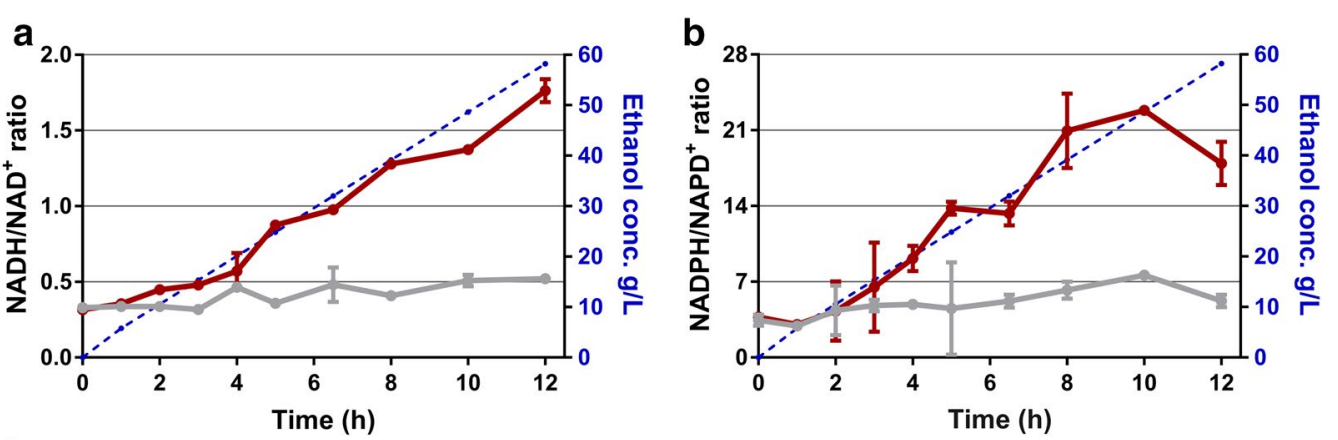

C

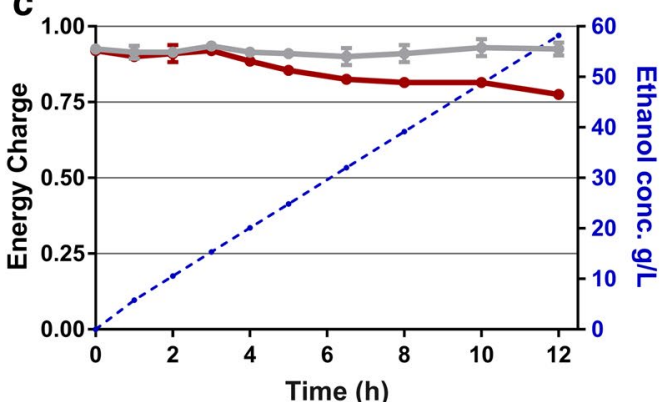

- No ethanol addition

With ethanol addition

-.. Ethanol concentration

Fig. 2 Nicotinamide cofactor ratios $(\mathbf{a}, \mathbf{b})$ and energy charges changes $(\mathbf{c})$ in C. thermocellum in the presence of added ethanol. The blue dashed line indicates the measured ethanol concentration of the culture with ethanol addition. Error bars represent one standard deviation, $n=3$ biological triplicates

ethanol). For T. saccharolyticum exposed to the same range of ethanol concentrations, no increases were found in the G6P/F6P and FBP pool while the DHAP pools increased by only twofold. Due to technical limitations of the LC-MS instrument, glyceraldehyde 3-phosphate (G3P) was not measured. 


\section{Cellobiose}

\section{Clostridium thermocellum}
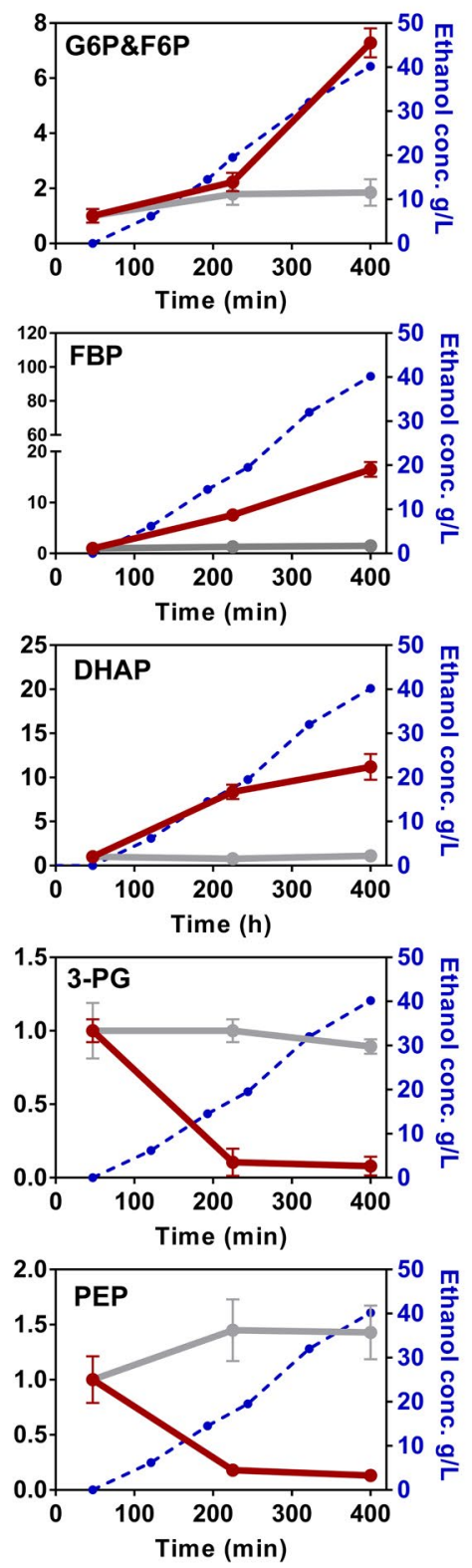

\section{- $\rightarrow$ - E Ethanol concentration \\ With Ethanol addtion \\ No Ethanol addition}

\section{Thermoanaerobacterium} saccharolyticum

\section{G6P(F6P)}
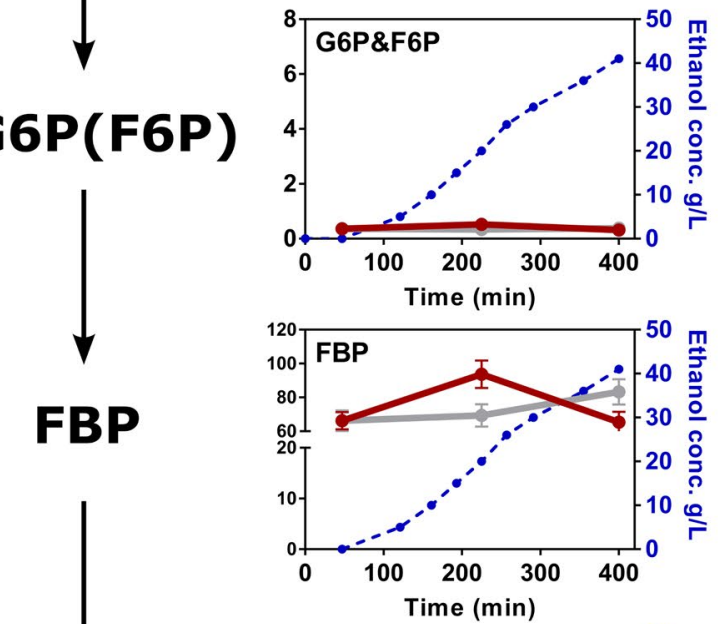

FBP
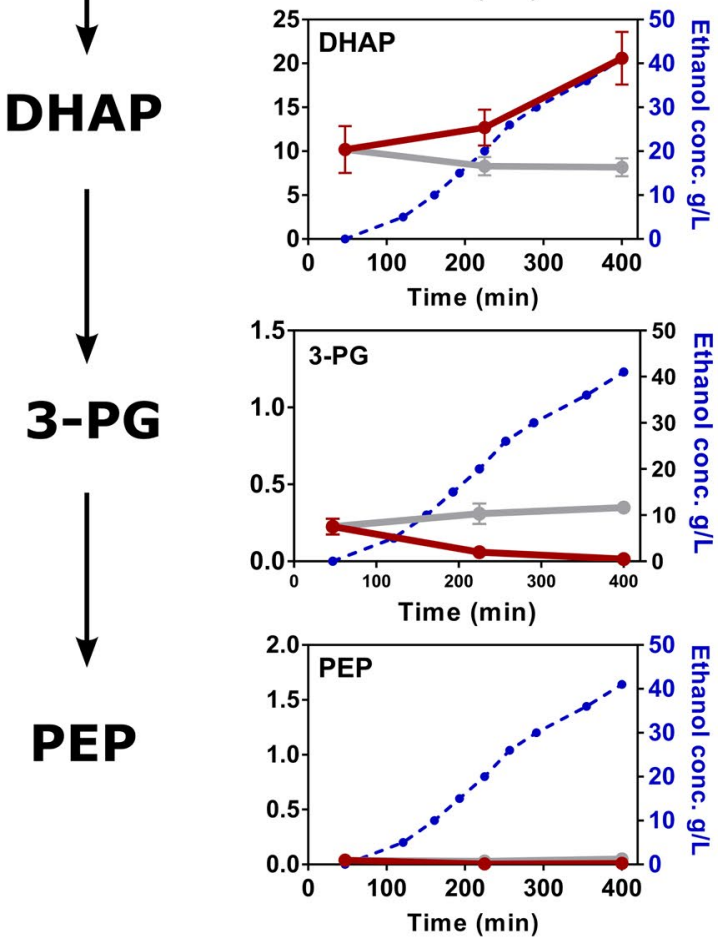

Fig. 3 Relative concentrations of intracellular metabolites for C. thermocellum and T. saccharolyticum in the presence of increasing ethanol concentrations. For each metabolite, values were normalized to the $C$. thermocellum T0 samples. Thus, the vertical axis represents a (unitless) ratio of metabolite concentrations. Error bars represent one standard deviation, $n=3$ biological triplicates. G6P glucose 6-phosphate, F6P fructose 6-phosphate, FBP fructose-1,6-bisphosphate, DHAP dihydroxyacetone phosphate, G3P glyceraldehyde 3-phosphate, 3-PG 3-phosphoglycerate, PEP phosphoenolpyruvate 
The different response of metabolite concentrations, to changes in added ethanol noted above, is consistent with a metabolic bottleneck in one of the steps in glycolysis between DHAP and 3-PG; that is, in reactions mediated by glyceraldehyde 3-phosphate dehydrogenase (GAPDH) or phosphoglycerate kinase (PGK).

Because the GAPDH reaction involves a nicotinamide cofactor and the redox state of such cofactors changed markedly in response to ethanol for both $C$. thermocellum and T. saccharolyticum (Additional file 4: Figure S1), we hypothesized that this enzyme (rather than PGK) might explain the difference in ethanol tolerance between the two strains.

\section{Comparison of Gapdh protein from C. thermocellum and $T$. saccharolyticum}

The gapdh genes from C. thermocellum (Clo1313_2095) and T. saccharolyticum (Tsac_2486) were expressed and purified in E. coli. The values of $K_{\mathrm{m}}$ and $V_{\max }$ for C. thermocellum Gapdh were $0.6 \pm 0.1 \mathrm{mM}$ and $17.8 \pm 2.1 \mathrm{~S}^{-1}$, respectively. The Gapdh of $T$. saccharolyticum exhibited similar kinetics with a $K_{\mathrm{m}}$ of $1.4 \pm 0.3 \mathrm{mM}$ and a $V_{\max }$ of $8.0 \pm 1.3 \mathrm{~S}^{-1}$. To compare their response to inhibition, their specific activities were measured with different $\mathrm{NADH} / \mathrm{NAD}^{+}$ratios (Fig. 4).

As may be seen from Fig. 4, the Gapdh from C. thermocellum (Ctherm_Gapdh) was much more sensitive to the $\mathrm{NADH} / \mathrm{NAD}^{+}$ratio. More than half of the activity was lost when the ratio was 0.2, whereas the Gapdh from T. saccharolyticum (Tsac_Gapdh) still had more than $90 \%$ of activity remaining. At a ratio of 1.0, the Ctherm Gapdh lost all activity, while 30\% of activity remained for the Tsac_Gapdh.

To analyze differences in the structure of the Gapdh proteins, homology models of the Ctherm_Gapdh and Tsac_Gapdh were constructed using the crystal structures of Oryza Sativa (Protein Data Bank code 3E5R, sharing $72.89 \%$ of identity) and Bacillus stearothermophilus (Protein Data Bank code 1GD1, sharing 79.52\% of identity), respectively [43]. These two models were aligned for comparison. Figure $5 \mathrm{a}$, c illustrates the structure of Ctherm_Gapdh from different angles. The location of the NADH cofactor in the active site can be clearly seen. Tsac_Gapdh had a similar catalytic cavity for NADH but with several differences in residues 99R, 183N, and 197R (Fig. 5b, d, indicated in red). These three residues are much larger than the corresponding residues in Ctherm_Gapdh (99V, 181A, and 196G) and these substitutions may partially restrict the entrance channel for NADH which may explain the higher $K_{\mathrm{m}}$. However, this change may also be the reason why Tsac_ Gapdh was less sensitive to inhibition by high NADH/ $\mathrm{NAD}^{+}$ratios [44].

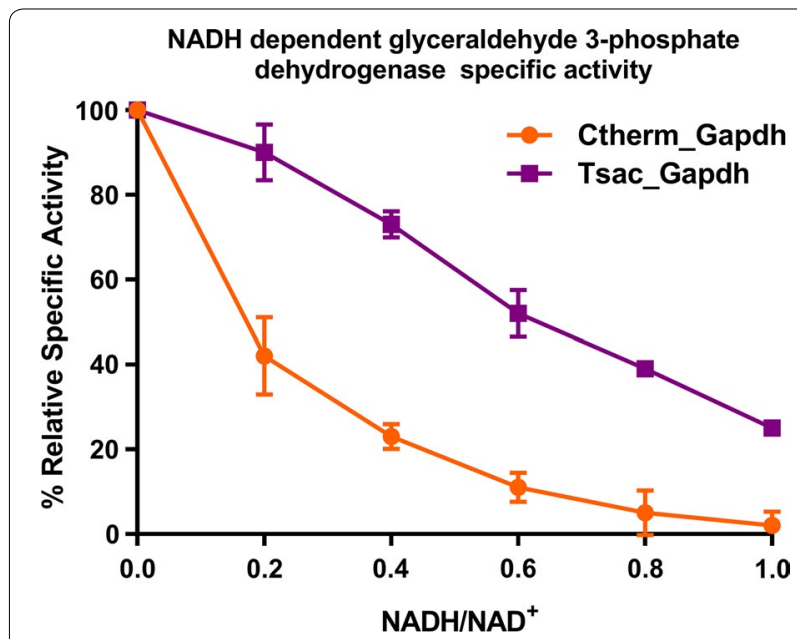

Fig. 4 Comparison of glyceraldehyde 3-phosphate dehydrogenase specific activities under different NADH/NAD ${ }^{+}$ratios. Error bars represent one standard deviation, $n=3$ biological triplicates

The performance of T. saccharolyticum Gapdh in C. thermocellum

The T. saccharolyticum gapdh was expressed in C. thermocellum to see if it would improve ethanol tolerance. Wild-type C. thermocellum and a strain overexpressing native gapdh were used as controls. The resulting strains were assayed for their ability to grow in the presence of 20 or $25 \mathrm{~g} / \mathrm{L}$ added ethanol (Fig. 6). The strain carrying the $T$. saccharolyticum gapdh showed improvement in growth at both concentrations of added ethanol. In addition, this strain consumed more cellulose after $80 \mathrm{~h} \mathrm{cul-}$ ture compared to the control strains.

To determine whether the increase in ethanol tolerance would affect ethanol production, the engineered strain and the wild-type control strain were both cultured in $50 \mathrm{~g} / \mathrm{L}$ Avicel in a bioreactor. Compared to the control strain, expression of the $T$. saccharolyticum gapdh increased ethanol titer by $28 \%$ (from $7.7 \pm 0.3$ to $9.9 \pm 0.5 \mathrm{~g} / \mathrm{L}$ ) (Additional file 5: Figure S2).

\section{Discussion and conclusions}

In this work, we analyzed the effect of added ethanol on the distribution of intracellular metabolites in C. thermocellum. As reviewed in the introduction, wild-type cultures of $C$. thermocellum and other thermophilic bacteria are generally able to initiate growth in the presence of only about $20 \mathrm{~g} / \mathrm{L}$ ethanol, but readily develop the ability to initiate growth at ethanol concentrations at least twofold higher after serial transfer over a period of weeks. We [18, 21] and others [19] have attributed this to genetic mutation followed by selection, and the mechanism has been confirmed by identifying a point mutation that confers the ethanol-tolerant phenotype in 


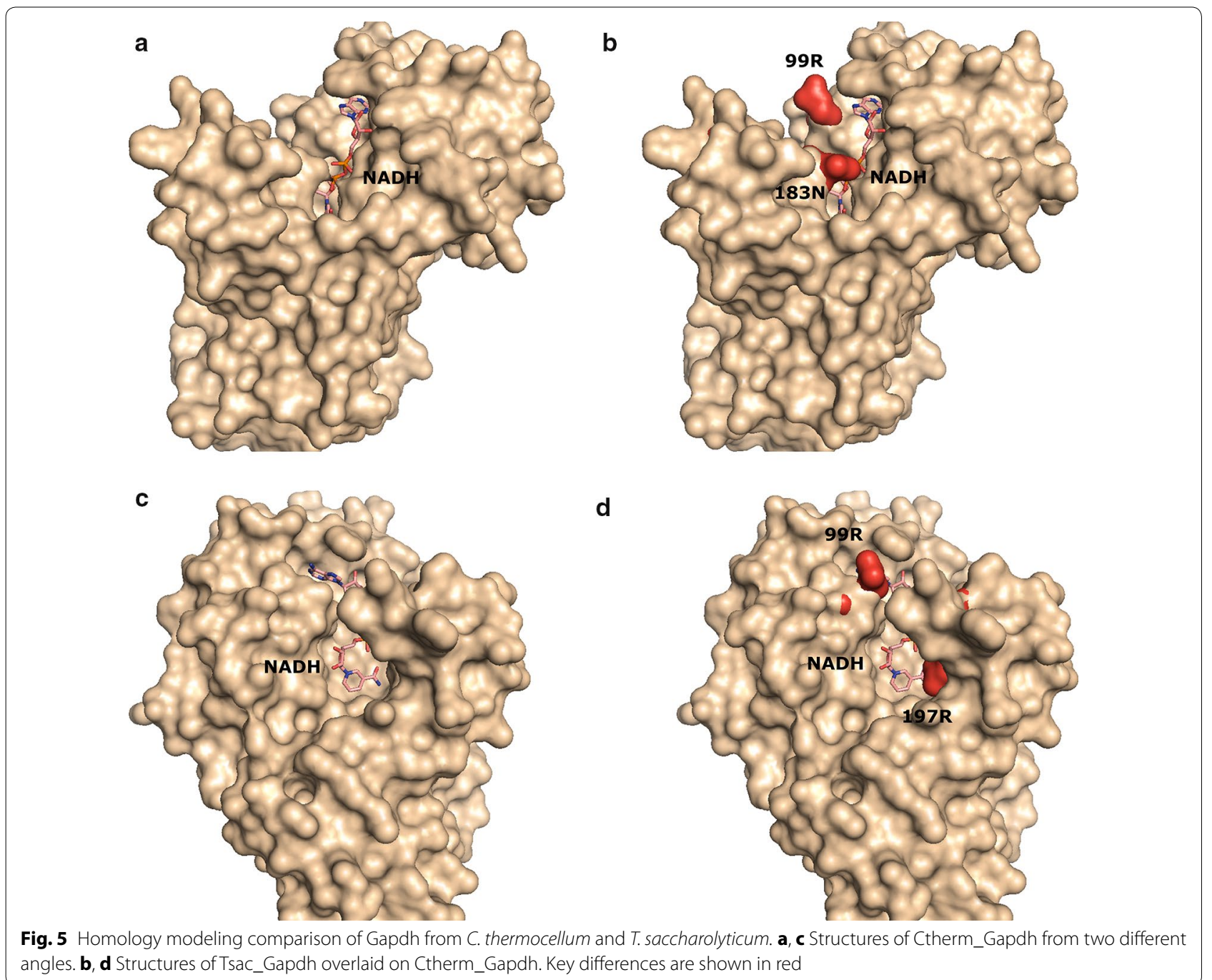

the absence of selection [21]. However, we observed in this study the ability to grow at ethanol concentrations exceeding $20 \mathrm{~g} / \mathrm{L}$ after exposure to ethanol for only $4 \mathrm{~h}$, which is very likely too short to be explained by mutation and selection [45]. Identifying the tolerance mechanism operative in the experiments described herein, as well as why tolerance is substantially greater to continuously added ethanol than to ethanol present initially, are interesting questions for future work, with important applied implications.

One of the leading hypotheses for ethanol inhibition is disruption of the cell membrane, which leads to loss of the proton motive force and subsequent decreased ability to generate ATP [27]. By directly measuring the adenylate charge, we have shown that added ethanol has no effect on ATP at concentrations below $15 \mathrm{~g} / \mathrm{L}$ and a negligible effect at higher concentrations (Fig. 2), which suggests that membrane disruption is not the primary cause of ethanol inhibition in C. thermocellum, at least for ethanol concentrations up to $45 \mathrm{~g} / \mathrm{L}$.

Another hypothesis for the mechanism of ethanol inhibition is that it affects specific metabolic enzymes. We observed a dramatic accumulation of NADH and $\mathrm{NADPH}$ when ethanol was added to the culture. Ethanol production in C. thermocellum involves successive reduction of acetyl-CoA and acetaldehyde with electrons provided by NADH (i.e., the ALDH and ADH reactions). The observed increase in the NADH/NAD ${ }^{+}$ratio in response to increasing ethanol is consistent with mass action. The concomitant increase in NADPH/NADP ${ }^{+}$ ratios is interesting to note and suggests that electrons may be exchanged between the two nicotinamide cofactor pools and/or that the oxidation state of these pools is controlled by a common factor. 

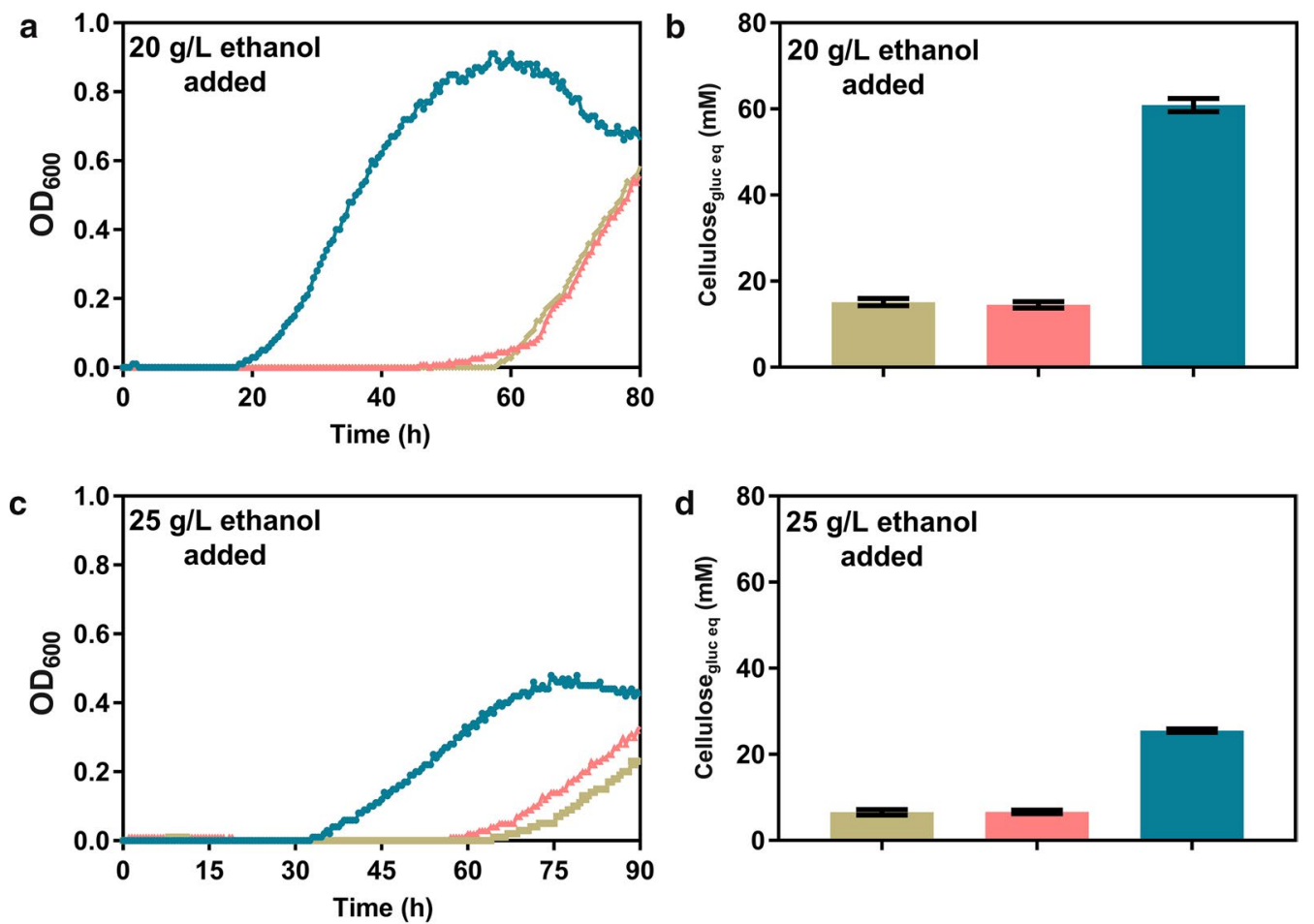

$\rightarrow$ C. thermoellum

C. thermoellum overexpressing Tsac_gapdh

C. thermoellum overexpressing Cthem_gapdh

Fig. 6 Growth of C. thermocellum strains expressing different gapdh genes in the presence of added ethanol. The data presented in panels $\mathbf{a}, \mathbf{c}$ are representative examples of growth curve data. Similar trends were found in all replicates. The data presented in panels $\mathbf{b}$, $\mathbf{d}$ are averages of cellulose consumption after $80 \mathrm{~h}$. Error bars represent one standard deviation, $n=3$ biological triplicates

Since NADH is known to be a competitive inhibitor of the GAPDH reaction [46-48], and we observe accumulation of metabolites upstream of the GAPDH reaction and depletion of reactions downstream of the GAPDH reaction, we conclude that, in the range of concentrations tested, ethanol inhibits $C$. thermocellum metabolism at the GAPDH reaction. Furthermore, T. saccharolyticum is more resistant to ethanol inhibition than C. thermocellum and also has a Gapdh enzyme that is more resistant to inhibition by high levels of NADH. To confirm this hypothesis, the T. saccharolyticum gapdh gene was overexpressed in C. thermocellum, resulting in dramatic improvements in ethanol tolerance: growth was initiated sooner, the growth rate was faster and substrate consumption was fourfold higher (Fig. 6).

Finally, we showed that this insight can be exploited for the practical purpose of increasing ethanol titer in C. thermocellum. Expressing the T. saccharolyticum gapdh gene in C. thermocellum increased ethanol titer by $28 \%$. Although this result by itself is a useful strategy for metabolic engineering of C. thermocellum, it also suggests a future line of work where engineering the Gapdh enzyme for improved tolerance to NADH could be used to further increase ethanol production C. thermocellum.

\section{Additional files}

Additional file 1: Table S1. Strain used in this work.

Additional file 2: Table S2. Plasmids used in this study.

Additional file 3: Table S3. Primers used in this study.

Additional file 4: Figure S1. Comparison of nicotinamide cofactor ratios between $C$. thermocellum and T. saccharolyticum in the presence of added ethanol. The absolute concentration of nicotinamide cofactors was determined based on a standard curve and normalized to cell number as determined by qPCR. Error bars represent one standard deviation, $n=3$ biological triplicates

Additional file 5: Figure S2. Fermentation profiles of $C$. thermocellum with or without the tsac_gapdh gene. Cells were grown in batch $\mathrm{pH}$-controlled fermenters with $50 \mathrm{~g} / \mathrm{L}$ Avicel. Error bars represent one standard deviation, $n=3$ biological triplicates. 


\begin{abstract}
Abbreviations
ADH: alcohol dehydrogenase; ALDH: aldehyde dehydrogenase; BSA: bovine serum albumin; CBP: consolidated bioprocessing; GAPDH: glyceraldehyde 3-phosphate dehydrogenase; PGK: phosphoglycerate kinase; MOPS: 3-morpholino-propane-1-sulfonic acid; G6P: glucose 6-phosphate; F6P: fructose 6-phosphate; FBP: fructose-1,6-bisphosphate; DHAP: dihydroxyacetone phosphate; G3P: glyceraldehyde 3-phosphate; 3-PG: 3-phosphoglycerate; PEP: phosphoenolpyruvic acid.
\end{abstract}

\section{Authors' contributions}

LT, DGO, and LRL designed experiments and wrote the manuscript. LT performed experiments and analyzed data. SP prepared the samples for metabolomic analysis. AL designed the GPCR method for cell number measurement. DAN, DS, and TJ performed metabolomic analysis and assisted with interpretation of the data. All authors read and approved the final manuscript.

\section{Author details}

${ }^{1}$ Thayer School of Engineering, Dartmouth College, 14 Engineering Drive, Hanover, NH 03755, USA. ${ }^{2}$ Dartmouth College, Hanover, NH 03755, USA. ${ }^{3}$ Bioenergy Science Center, Oak Ridge National Laboratory, Oak Ridge, TN 37831, USA. ${ }^{4}$ University of Wisconsin-Madison, Madison, WI 53706, USA.

\section{Acknowledgements}

The BioEnergy Science Center is a US Department of Energy Bioenergy Research Center supported by the Office of Biological and Environmental Research in the DOE Office of Science. This manuscript has been authored by Dartmouth College under Contract No. DE-AC05-00OR22725 with US Department of Energy. The US Government retains and the publisher, by accepting the article for publication, acknowledges that the US Government retains a non-exclusive, paid-up, irrevocable worldwide license to publish or reproduce the published form of this manuscript or allow others to do so, for US Government purposes.

\section{Competing interests}

Lee R. Lynd is a founder of the Enchi Corporation, which has a financial interest in C. thermocellum. No non-financial competing interests exist for any of the authors.

\section{Availability of supporting data}

The datasets used in this study are included in the published article and its additional information files. Raw metabolomic data is available upon request.

\section{Consent for publication}

Not applicable.

\section{Ethical approval and consent to participate} Not applicable.

\section{Funding}

The BioEnergy Science Center is a US Department of Energy Bioenergy Research Center supported by the Office of Biological and Environmental Research in the DOE Office of Science.

\section{Publisher's Note}

Springer Nature remains neutral with regard to jurisdictional claims in published maps and institutional affiliations.

Received: 2 August 2017 Accepted: 6 November 2017

Published online: 30 November 2017

\section{References}

1. Lynd LR, Weimer PJ, van Zyl WH, Isak S. Microbial cellulose utilization: fundamentals and biotechnology. Microbiol Mol Biol Rev. 2002;66:506-77.

2. Lynd L, van Zyl WH, McBride J, Laser M. Consolidated bioprocessing of cellulosic biomass: an update. Curr Opin Biotechnol. 2005;16:577-83.

3. Olson DG, McBride JE, Shaw AJ, Lynd LR. Recent progress in consolidated bioprocessing. Curr Opin Biotechnol. 2012;23:396-405.
4. Lynd LR, Liang X, Biddy MJ, Allee A, Cai H, Foust T, et al. Cellulosic ethanol: status and innovation. Curr Opin Biotechnol. 2017;45:202-11.

5. Lynd LR, Guss AM, Himmel ME, Beri D, Herring C, Holwerda EK, et al. Advances in consolidated bioprocessing using Clostridium thermocellum and Thermoanaerobacter saccharolyticum. Ind Biotechnol. 2016;10:365-94.

6. Paye JMD, Guseva A, Hammer SK, Gjersing E, Davis MF, Davison BH, et al. Biological lignocellulose solubilization: comparative evaluation of biocatalysts and enhancement via cotreatment. Biotechnol Biofuels. 2016;9:8.

7. Balch ML, Holwerda EK, Davis MF, Sykes RW, Happs RM, Kumar R, et al. Environmental science lignocellulose fermentation and residual solids characterization for senescent switchgrass fermentation by Clostridium thermocellum. Energy Environ Sci. 2017;10:1252-61.

8. Papanek B, Biswas R, Rydzak T, Guss AM. Elimination of metabolic pathways to all traditional fermentation products increases ethanol yields in Clostridium thermocellum. Metab Eng. 2015;32:49-54.

9. Tian L, Lo J, Shao X, Zheng T, Olson DG, Lynd R. Ferredoxin:NAD ${ }^{+}$oxidoreductase of Thermoanaerobacterium saccharolyticum and its role in ethanol formation. Appl Environ Microbiol. 2016;82:7134-41.

10. Tian L, Papanek B, Olson DG, Rydzak T, Holwerda EK, Zheng T, et al. Simultaneous achievement of high ethanol yield and titer in Clostridium thermocellum. Biotechnol Biofuels. 2016;9:116.

11. Lo J, Olson DG, Murphy SJ-L, Tian L, Hon S, Lanahan A, et al. Engineering electron metabolism to increase ethanol production in Clostridium thermocellum. Metab Eng. 2017;39:71-9.

12. Hon S, Olson DG, Holwerda EK, Lanahan AA, Murphy SJL, Maloney MI, et al. The ethanol pathway from Thermoanaerobacterium saccharolyticum improves ethanol production in Clostridium thermocellum. Metab Eng. 2017:42:175-84.

13. Tian L, Perot SJ, Hon S, Zhou J, Liang X, Bouvier JT, Guss AM, Olson DG Lynd LR. Enhanced ethanol formation by Clostridium thermocellum via pyruvate decarboxylase. Microb Cell Fact. 2017;16:171.

14. Dien BS, Cotta MA, Jeffries TW. Bacteria engineered for fuel ethanol production: current status. Appl Microbiol Biotechnol. 2003;63:258-66.

15. Herring CD, Kenealy WR, Shaw AJ, Covalla SF, Olson DG, Zhang J, et al. Strain and bioprocess improvement of a thermophilic anaerobe for the production of ethanol from wood. Biotechnol Biofuels. 2016;9:125.

16. Demain AL, Newcomb M, Wu JHD. Cellulase, clostridia, and ethanol. Microbiol Mol Biol Rev. 2005;69:124-54.

17. Woodruff LB, Boyle NR, Gill RT. Engineering improved ethanol production in Escherichia coli with a genome-wide approach. Metab Eng. 2013;17:1-11.

18. Shao X, Raman B, Zhu M, Mielenz JR, Brown SD, Guss AM, et al. Mutant selection and phenotypic and genetic characterization of ethanoltolerant strains of Clostridium thermocellum. Appl Microbiol Biotechnol. 2011;92:641-52.

19. Williams TI, Combs JC, Lynn BC, Strobel HJ. Proteomic profile changes in membranes of ethanol-tolerant Clostridium thermocellum. Appl Microbiol Biotechnol. 2007;74:422-32.

20. Timmons MD, Knutson BL, Nokes SE, Strobel HJ, Lynn BC. Analysis of composition and structure of Clostridium thermocellum membranes from wild-type and ethanol-adapted strains. Appl Microbiol Biotechnol. 2009;82:929-39.

21. Brown SD, Guss AM, Karpinets TV, Parks JM, Smolin N, Yang S, et al. Mutant alcohol dehydrogenase leads to improved ethanol tolerance in Clostridium thermocellum. Proc Natl Acad Sci USA. 2011;108:13752-7.

22. Sudha Rani K, Seenayya G. High ethanol tolerant Clostridium thermocellum strains SS21 and SS22. J Sci Ind Res. 1998;57:634-9.

23. Herrero A, Gomez R, Roberts M. Ethanol-induced changes in the membrane lipid composition of Clostridium thermocellum. Biochim Biophys Acta. 1982;693:195-204.

24. Herrero AA, Gomez RF, Roberts MF. ${ }^{31}$ P NMR studies of Clostridium thermocellum. Mechanism of end product inhibition by ethanol. J Biol Chem. 1985;260:7442-51.

25. Lovitt RW, Shen GJ, Zeikus JG. Ethanol production by thermophilic bacteria: biochemical basis for ethanol and hydrogen tolerance in Clostridium thermohydrosulfuricum. J Bacteriol. 1988;170:2809-15.

26. Woodruff LBA, May BL, Warner JR, Gill RT. Towards a metabolic engineering strain "commons": an Escherichia coli platform strain for ethanol production. Biotechnol Bioeng. 2013;110:1520-6. 
27. Dunlop MJ. Engineering microbes for tolerance to next-generation biofuels. Biotechnol Biofuels. 2011:4:32.

28. Tolonen AC, Zuroff TR, Mohandass R, Boutard M, Cerisy T, Curtis WR. Physiology, genomics, and pathway engineering of an ethanol-tolerant strain of Clostridium phytofermentans. Appl Environ Microbiol. 2015;81:5440-8.

29. Biswas R, Prabhu S, Lynd LR, Guss AM. Increase in ethanol yield via elimination of lactate production in an ethanol-tolerant mutant of Clostridium thermocellum. PLOS ONE. 2014;9:e86389.

30. Bennett BD, Yuan J, Kimball EH, Rabinowitz JD. Absolute quantitation of intracellular metabolite concentrations by an isotope ratio-based approach. Nat Protoc. 2008;3:1299-311.

31. Yang S, Giannone RJ, Dice L, Yang ZK, Engle NL, Tschaplinski TJ, et al. Clostridium thermocellum ATCC27405 transcriptomic, metabolomic and proteomic profiles after ethanol stress. BMC Genom. 2012;13:336.

32. RydzakT, Levin DB, Cicek N, Sparling R. End-product induced metabolic shifts in Clostridium thermocellum ATCC 27405. Appl Microbiol Biotechnol. 2011;92:199-209.

33. Holwerda EK, Thorne PG, Olson DG, Amador-Noguez D, Engle NL, Tschaplinski TJ, et al. The exometabolome of Clostridium thermocellum reveals overflow metabolism at high cellulose loading. Biotechnol Biofuels. 2014;7:155.

34. Lynd LR, Baskaran S, Casten S. Salt accumulation resulting from base added for $\mathrm{pH}$ control, and not ethanol, limits growth of Thermoanaerobacterium thermosaccharolyticum HG-8 at elevated feed xylose concentrations in continuous culture. Biotechnol Prog. 2001;17:118-25.

35. Lo J, Zheng T, Olson DG, Ruppertsberger N, Tripathi SA, Tian L, et al. Deletion of nfnAB in Thermoanaerobacterium saccharolyticum and its effect on metabolism. J Bacteriol. 2015;197:3367.

36. Holwerda EK, Hirst KD, Lynd LR. A defined growth medium with very low background carbon for culturing Clostridium thermocellum. J Ind Microbiol Biotechnol. 2012;39:943-7.

37. Zhou J, Olson DG, Lanahan AA, Tian L, Murphy SJ-L, Lo J, et al. Physiological roles of pyruvate ferredoxin oxidoreductase and pyruvate formatelyase in Thermoanaerobacterium saccharolyticum JW/SL-YS485. Biotechnol Biofuels. 2015:8:138.
38. Olson DG, Hörl M, Fuhrer T, Cui J, Zhou J, Maloney MI, et al. Glycolysis without pyruvate kinase in Clostridium thermocellum. Metab Eng. 2016;39:169-80.

39. Clasquin MF, Rabinowitz EM and JD. LC-MS data processing with MAVEN: a metabolomic analysis and visualization engine. Curr Protoc Bioinform. 2012. https://doi.org/10.1002/0471250953.bi1411s37

40. Melamud E, Vastag L, Rabinowitz JD. Metabolomic analysis and visualization engine for LC-MS data. Anal Chem. 2010;82:9818-26.

41. Holwerda EK, Ellis LD, Lynd LR. Development and evaluation of methods to infer biosynthesis and substrate consumption in cultures of cellulolytic microorganisms. Biotechnol Bioeng. 2013;110:2380-8.

42. Zwickl P, Fabry S, Bogedain C, Haas A, Hensel R. Glyceraldehyde3-phosphate dehydrogenase from the hyperthermophilic archaebacterium Pyrococcus woesei: characterization of the enzyme, cloning and sequencing of the gene, and expression in Escherichia coli. J Bacteriol. 1990;172:4329-38.

43. Skarzynski T, Moody PCE, Wonacott AJ. Structure of holo-glyceraldehyde3-phosphate dehydrogenase from Bacillus stearothermophilus at $1.8 \AA$ resolution. J Mol Biol. 1987;193:171-87.

44. Sun Z, Do PM, Rhee MS, Govindasamy L, Wang Q, Ingram LO, et al. Amino acid substitutions at glutamate-354 in dihydrolipoamide dehydrogenase of Escherichia coli lower the sensitivity of pyruvate dehydrogenase to NADH. Microbiology. 2012;158:1350-8.

45. Harder A, Roels JA. Application of simple structured models in bioengineering. In: Microbes and engineering aspects. Berlin: Springer; 1982. p. 55-107.

46. Willquist K, Pawar SS, Van Niel EWJ. Reassessment of hydrogen tolerance in Caldicellulosiruptor saccharolyticus. Microb Cell Fact. 2011;10:111.

47. Copeland L. Kinetic properties of NAD-dependent glyceraldehyde3-phosphate dehydrogenase from the host fraction of soybean root nodules. Arch Biochem Biophys. 1994;312:107-13.

48. Even S, Garrigues C, Loubiere P, Lindley ND, Cocaign-Bousquet M. Pyruvate metabolism in Lactococcus lactis is dependent upon glyceraldehyde-3-phosphate dehydrogenase activity. Metab Eng. 1999;1:198-205.

\section{Submit your next manuscript to BioMed Central and we will help you at every step:}

- We accept pre-submission inquiries

- Our selector tool helps you to find the most relevant journal

- We provide round the clock customer support

- Convenient online submission

- Thorough peer review

- Inclusion in PubMed and all major indexing services

- Maximum visibility for your research

Submit your manuscript at www.biomedcentral.com/submit
() Biomed Central 